\title{
Yüksek Yoğunluklu Lif Levhanın Bazı Özellikleri Üzerine Dolomit Mineralinin Etkisinin Araştırılması
}

\author{
Ferhat ÖZDEMIR* \\ Kahramanmaras Sütcü İmam Üniversitesi, Orman Fakültesi, Orman Endüstri Mühendisliği Bölümü, \\ Kahramanmaras, Türkiye.
}

ÖZET: Bu çalışmada yanmayı geciktirici dolomit mineralinin yüksek yoğunluklu lif levhanın (HDF) bazı fiziksel, mekanik ve yanma özellikleri üzerine etkisi araştırılmıştır. Odun lifi olarak \%50 Kayın ve \%50 sarıçam lifleri kullanılmıştır. Liflerin içerisine tam kuru lif miktarına oranla $\% 5, \% 10, \% 15, \% 20$ ve $\% 25$ oranlarında toz halinde dolomit minerali tozu ilave edilerek $6.5 \mathrm{~mm}$. kalınlıkta HDF levhalar elde edilmiștir. Dolomit mineralinin eklenmesi ile HDF levhaların su alma ve kalınlığına şişme özelliklerinin olumsuz etkilendiği bulunmuştur. Bunun yanı sıra eğilme direnci ve elastikiyet modülü de olumsuz etkilenmiştir. Ancak dolomit minerali eklenmesi ile HDF levhaların yanmaya karşı direnç özelliklerinin arttı̆̆ belirlenmiş̧ir.

Anahtar kelimeler: Dolomit, HDF, Yanma direnci, Fiziksel özellikler,

\section{Investigate on effect of dolomite mineral on some properties of high density fiberboard (HDF)}

\begin{abstract}
In this study, the effect of dolomite mineral on some physical, mechanical properties and combustion resistance of high density fiberboard (HDF) were investigated. Beach (Fagus Sylvatica) and Scots pine (Pinus Sylvestris $L$.) fiber (a 50:50 blend) were used as wood fiber. HDF boards were produced in $6.5 \mathrm{~mm}$ thickness through adding 5\%,10\%, 15\%, 20\% and 25\% dolomite powder into the fiber. It was found out that thickness swelling properties of HDF boards were negatively affected with the added of dolomite mineral. Additionally, bending strength and modulus of elasticity were adversely affected. However, it was determined that fire resistance properties of HDF boards were improved with addition of dolomite mineral.
\end{abstract}

Keywords: Dolomite, HDF, Fire resistance, Physical properties

\section{GíRIS}

Ahşap esaslı levhalar iyi fiziksel ve mekanik özelliklere sahip olmalarının yanı sıra düşük maliyetleri ile istenilen kalınlık ve yoğunluk ta elde edilebilmelerinden dolayı mobilya, dekorasyon, inşaat, taşıma ve diğer endüstri kollarında geniş bir kullanım alanı bulmaktadır. Ahşap ve ahşap esaslı levhaların kullanım avantajlarının yanı sıra dezavantajları da bulunmaktadır. Ahşap ve ahşap esaslı levhalar yapısal özelliklerinden dolayı fiziksel, kimyasal, biyolojik bozunma ve yanmaya karşı dirençleri hassas bir durumdadır [1]. Günümüzde yaygın şekilde kullanılan lif levhaların yanıcı olma özelliği kullanım alanını sinırlandırmaktadır. Bu nedenle lif levhalara yanmayı geciktirici özellik kazandırılması gerekmektedir [2].

Yanmayı geciktirici kimyasal maddeler kompozit üretimi esnasında toz halinde tutkala, odun yongasına veya odun lifine katılmaktadır [3]. Ahşap ve ahşap esaslı levhalarda en çok kullanılan yanmayı geciktirici kimyasal maddeler fosforik asit, monoamonyumfosfat gibi inorganik tuzlar ve boraks, borik asit, çinko klorür gibi bor bileşikleridir [4]. İnorganik tuzlar ahşap ve ahşap esaslı levhaların higroskopisitesini artırır ve metaller ile temasında korozyona sebep olabilirler. Bor bileşikleri ise bağ yapmaması nedeni ile düşük yapışma özelliği gösterdiği için mekanik özellikleri azaltmaktadır. Dolomit ise yanmayı geciktirici olarak kullanılması mümkün olan alternatif bir mineraldir. Ülkemizde bol miktarda dolomit bulunmaktadır. Borlu bileşikler kompozit üretimi esnasında toz halinde tutkala, odun yongasına veya odun lifine katılmaktadır [3]. Bor bileşiklerine alternatif olarak dolomitin yüksek kalsiyum ve magnezyum içeriğine sahip olması nedeni ile yanmaya karşı doğal bir direnç sağlayacağı düşünülmektedir [5]. Dolomit, kireçtaşında $\left(\mathrm{CaCO}_{3}\right) \mathrm{Ca}$ ile beraber $\mathrm{Mg}^{\prime}$ un yer alması ile oluşan bir mineraldir. Özgül ağırlığı Mg oranına bağlı olarak 2,71 ile 2,87 $\mathrm{Ton} / \mathrm{m}^{3}$, sertlik ise 3,5-4 arasındadır. Dolomit, basta demir-çelik sanayi olmak üzere cam, seramik, boya, gübre, tuğla, çimento ve inşaat sanayilerinde, tarımda toprak ıslahı gibi çok geniş bir alanda kullanılmaktadır. Dünya'da ve Türkiye'de oldukça geniş bir yayılıma sahip olup rezerv problemi olmayan bir mineraldir. Dünya'da dolomit büyük miktarlarda ve çok değişik sektörlerde 
kullanılmasına rağmen Türkiye'de üretimin çok önemli bölümü sadece demir - çelik ve cam sanayinde kullanılmaktadır. Bu çalışma ile dolomitin ahşap esaslı ürün sanayinde kullanılabilirliği araştırılacaktır.

Bu çalışmanın amacı yüksek yoğunluklu lif levha üretiminde liflerin içerisine katılan dolomit mineralinin levhanın fiziksel, mekanik ve yanma direnci özellikleri üzerine etkilerini belirlemek olacaktır.

\section{MATERYAL ve METOT}

\subsection{Materyal}

Bu çalışmada lif hammaddesi olarak \%10 tutkallı sarıçam (Pinus Sylvestris L.) (\%50) ve kayın (Fagus Sylvatica) (\%50) lif karışımı kullanılmıştır. Lifler Kastamonu Entegre Tic. A.Ş. den elde edilmiştir. Yanmayı geciktirici kimyasal olarak kullanılan dolomit minerali tozu Doltaş Madencilik ve Kimya San. Tic. Ltd. Şti' den elde edilmiştir.

Üretimde kullandığımız dolomit mineralinin Dokuz Eylül Üniversitesi tarafından yapılmış olan kimyasal analiz sonuçları Tablo1' de verilmiştir.

Tablo 1. Dolomit minerali kimyasal analiz sonuçları

\begin{tabular}{|l|c|}
\hline \multicolumn{2}{|c|}{ Dolomit Minerali } \\
\hline Kimyasal bileşimi & $\mathrm{CaMg}\left(\mathrm{CO}_{3}\right)_{2}$ \\
\hline Kristal sistemi & $\mathrm{Hegzagonal}$ \\
\hline Sertlik & $3.5-4$ \\
\hline Özgül ağırlık & 2.86 \\
\hline Beyazlık Oranı (\%) & 98 \\
\hline $\mathrm{CaO}(\%)$ & 31.10 \\
\hline $\mathrm{MgO}(\%)$ & 21.04 \\
\hline $\mathrm{Fe}_{2} \mathrm{O}_{3}(\%)$ & 0.03 \\
\hline $\mathrm{SiO}_{2}(\%)$ & 0.22 \\
\hline $\mathrm{Al}_{2} \mathrm{O}_{3}(\%)$ & 0.02 \\
\hline $\mathrm{Na}_{2} \mathrm{O}(\%)$ & $<0.01$ \\
\hline $\mathrm{K}_{2} \mathrm{O}(\%)$ & $<0.01$ \\
\hline $\mathrm{K} . \mathrm{Kayb}_{1} 1000^{\circ} \mathrm{C}$ & 47.57 \\
\hline
\end{tabular}

\subsubsection{HDF levhaların hazırlanması}

Tablo 2' de liflerin içerisine katılan dolomit tozu ve karışım \% oranları verilmiştir. Tutkal olarak üre formaldehit tutkalı (katı madde miktarı \%55, özgül ağırlık $1.23 \mathrm{gr} / \mathrm{cm}^{3}$ ) kullanılmış ve tam kuru lif oranına bağlı olarak \%10 oranında muamele edilmiştir. Dolomit minerali (Dol) tozu tam kuru lif ağırlığına oranla \%5, $\% 10, \% 15, \% 20$ ve $\% 25$ oranlarında lif içerisine homojen şekilde karıştırılmıştır. Soğuk preste taslak oluşturulmuş ve daha sonra Tablo 3' de verilen basınç şartlarına uygun olarak Cemil Usta SSP 120 pres makinesin de sicak pres uygulanmıştır. 300x300x6.5 mm boyutlarında ve 1.05 $1.13 \mathrm{~g} / \mathrm{cm}^{3}$ yoğunlukta levhalar üretilmiştir. Levhalar daha sonra iki hafta süre ile $65 \pm 5 \%$ bağ 1 nem ve $20 \pm 2$
${ }^{0} \mathrm{C}$ sıcaklıkta klimatize edilmiştir. Levhaların fiziksel, mekanik ve yanma direnci özelliklerini belirlemek için ilgili standartlara uygun şekilde kontrol ve deney örnekleri kesilmiş klimatize edilmiştir.

Tablo 2. HDF levha üretiminde kullanılan dolomit mineral madde ve oranları

\begin{tabular}{|c|c|c|}
\hline $\begin{array}{l}\text { Üretilen } \\
\text { Levha } \\
\text { Sayısı }\end{array}$ & Mineral madde & $\operatorname{Oran}^{\mathrm{a}}(\%)$ \\
\hline 3 & Kontrol & $\overline{---}$ \\
\hline 3 & Dol & 05 \\
\hline 3 & Dol & 10 \\
\hline 3 & Dol & 15 \\
\hline 3 & Dol & 20 \\
\hline 3 & Dol & 25 \\
\hline \multirow{2}{*}{\multicolumn{2}{|c|}{$\begin{array}{l}\text { Üre formaldehit tutalı } \\
\text { Sertleştirici (Amonyum } \\
\text { Klorür/ } / \mathrm{NH}_{4} \mathrm{Cl} \text { ) }\end{array}$}} & 10 \\
\hline & & 0.5 \\
\hline
\end{tabular}

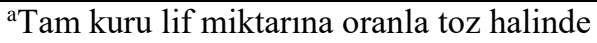

Tablo 3. HDF levha üretim pres parametreleri

\begin{tabular}{|c|c|}
\hline \multicolumn{2}{|c|}{ Parametreler } \\
\hline Sicaklık $\left({ }^{\circ} \mathrm{C}\right)$ & 190 \\
\hline Basınç $(\mathrm{MPa})$ & 3.5 \\
\hline Süre $(\mathrm{s})$ & 40 \\
\hline
\end{tabular}

\subsection{Metot}

\subsubsection{Fiziksel ve Mekanik Testler}

HDF levhaların 2 ve 24 saat su alma ve kalınlığına şişme özellikleri [6] EN 317 (1999), eğilme ve elastikiyet modülü testleri [7] EN 310 standartlarına göre yapılmıştır.

\subsubsection{Limit Oksijen İndeks (LOI)Testi}

Belirli oranlarda dolomit minerali ilave edilmiş liflerden elde edilen levhaların oksijen indeksi testi Ortadoğu Teknik Üniversitesi Mühendislik (ODTÜ) Fakültesi Kimya Mühendisliği Bölümü Laboratuarında ASTM 2863 - 09 (2006) [8] standardına uygun olarak (örnek boyutu: 100x15x0.65 mm) yapılmıştır. 4 adet test, 4 adet ise kontrol örneği hazırlanmıştır. Örnekler LOI test cihazına (Şekil 1) dikey olarak yerleştirilmiş, kolonun alt kısmından oksijen ve nitrojen hava akımı başlatılmış ve deney numuneleri üst kısımdan yakılmıştır. Test numunesinin yanması için yeterli oksijen miktarı hava akımı içinde tespit edilmiştir.

Fiziksel ve mekanik özelliklerin istatistik analizi için SSPS paket programı kullanılmıştır. 2 ve 24 saat su alma, kalınlığına şişme ile eğilme direnci ve elastikiyet modülü testi için One way ANOVA \%95 güven düzeyinde $\mathrm{P} \leq 0.05$ olarak hesaplanmıştır. Farkların anlamlı bulunması nedeni ile grupları belirlemek için Duncan ayrım testi yapılmıştır. 


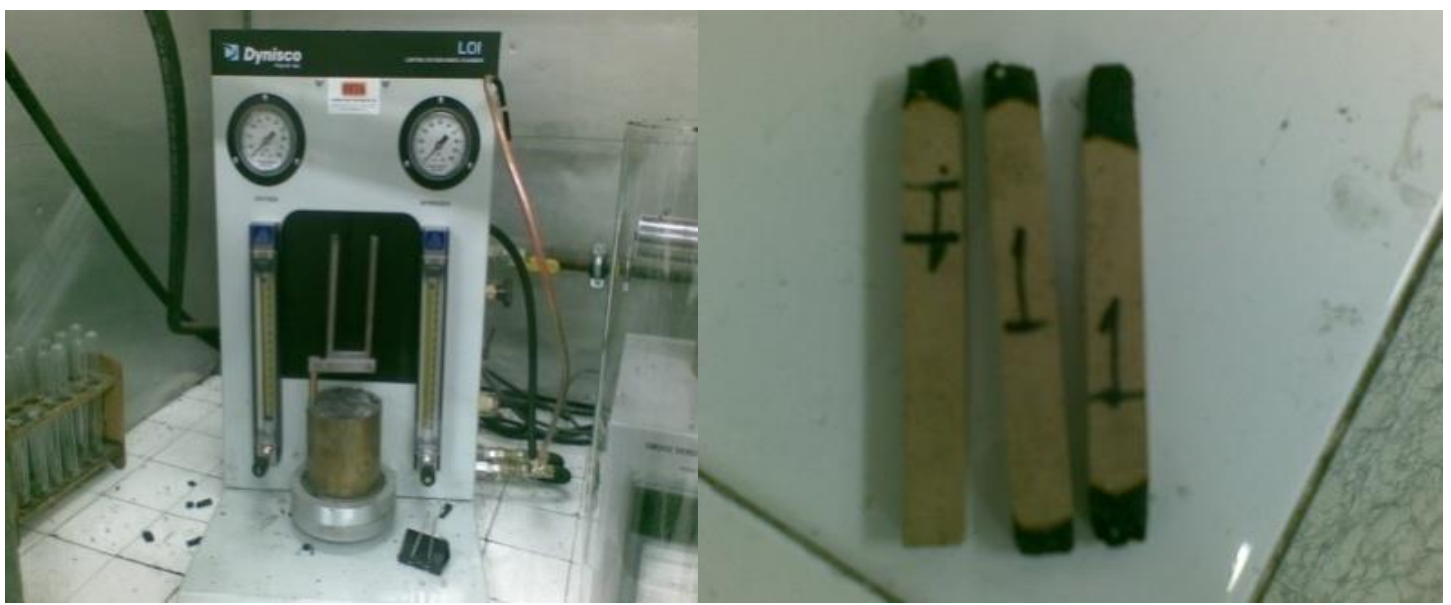

Şekil 1. Limit oksijen indeksi ölçüm cihazı ve test numune örnekleri

\section{BULGULAR VE TARTIŞMA}

\subsection{Fiziksel ve Mekanik Özelliklere ait Bulgular}

HDF levhaların yoğunluk değerleri ile 2 ve 24 saat su alma, kalınlığına şişme değerleri ve istatistik değerlendirmeleri Tablo 4' de verilmiştir. Tablo 4'de görüldüğü üzere üretilen HDF levhaların yoğunluk ölçümlerinin 1.05-1.13 g/cm3 arasında değiştiği belirlenmiştir. Dolomit tozu eklenerek elde edilen HDF levhaların tüm gruplarında su alma ve kalınlık şişme miktarı kontrol levhaların ölçüm değerlerinden daha yüksek olduğu tespit edilmiştir. 2 saat süre sonunda su alma miktarı kontrol örneğinde \%12.38 iken en fazla dolomit \%25 levha örneklerinde \%14.88 olarak bulunmuştur. 24 saat su alma ölçümlerinde ise kontrol örneği \%52.81 iken dolomit \%25 levha örnekleri ortalama ölçümleri \%59.01 olmuştur. Su alma miktarı levha üretiminde kullanılan dolomit mineral miktarının konsantrasyon artışına bağlı olarak artmıştır.

Tablo 4. HDF levhaların 2 ve 24 saat su alma ve kalınlık şişme ölçümleri

\begin{tabular}{|c|c|c|c|c|c|c|}
\hline \multirow{2}{*}{ Mineral madde } & \multirow{2}{*}{$\frac{\text { Yoğunluk }}{\mathrm{g} / \mathrm{cm}^{3}}$} & & \multicolumn{2}{|c|}{ Kalınlık (\%) } & \multicolumn{2}{|c|}{ Su Alma (\%) } \\
\hline & & & 2 saat & 24 saat & 2 saat & 24 saat \\
\hline \multirow{2}{*}{ Dol \%05 } & \multirow{2}{*}{1.07} & $\mathrm{X}$ & $13.72^{\mathrm{b}}$ & $43.20^{\mathrm{b}}$ & $13.55^{\mathrm{b}}$ & $54.68^{b}$ \\
\hline & & $\mathrm{S}$ & $(0.66)$ & $(0.88)$ & $(0.32)$ & $(0.54)$ \\
\hline \multirow{2}{*}{ Dol \%10 } & \multirow{2}{*}{1.08} & $\mathrm{X}$ & $14.18^{\mathrm{bc}}$ & $44.05^{\mathrm{c}}$ & $13.85^{\mathrm{bc}}$ & $55.46^{\mathrm{c}}$ \\
\hline & & $\mathrm{S}$ & $(0.69)$ & $(0.83)$ & $(0.32)$ & $(0.53)$ \\
\hline \multirow{2}{*}{ Dol \%15 } & \multirow{2}{*}{1.09} & $\mathrm{X}$ & $14.69^{\mathrm{cd}}$ & $46.06^{\mathrm{d}}$ & $14.02^{\mathrm{cd}}$ & $56.22^{\mathrm{d}}$ \\
\hline & & $\mathrm{S}$ & $(0.88)$ & $(0.87)$ & $(0.41)$ & $(0.44)$ \\
\hline \multirow{2}{*}{ Dol \%20 } & \multirow{2}{*}{1.11} & $\mathrm{X}$ & $15.23^{\mathrm{de}}$ & $47.45^{\mathrm{e}}$ & $14.33^{\mathrm{d}}$ & $57.94^{\mathrm{e}}$ \\
\hline & & $\mathrm{S}$ & $(0.83)$ & $(0.92)$ & $(0.42)$ & $(0.53)$ \\
\hline \multirow{2}{*}{ Dol \%25 } & \multirow{2}{*}{1.13} & $\mathrm{X}$ & $15.72^{\mathrm{d}}$ & $48.51^{\mathrm{f}}$ & $14.88^{\mathrm{e}}$ & $59.01^{\mathrm{f}}$ \\
\hline & & $\mathrm{S}$ & $(0.89)$ & $(0.73)$ & $(0.57)$ & $(0.47)$ \\
\hline \multirow{2}{*}{ Kontrol } & \multirow{2}{*}{1.05} & $\mathrm{X}$ & $11.34^{\mathrm{a}}$ & $40.55^{\mathrm{a}}$ & $12.38^{\mathrm{a}}$ & $52.81^{\mathrm{a}}$ \\
\hline & & $\mathrm{S}$ & $(0.30)$ & $(0.80)$ & $(0.37)$ & $(0.43)$ \\
\hline Duncan Testi P Değeri & --- & Sig. & 0.000 & 0.000 & 0.000 & 0.000 \\
\hline
\end{tabular}

a,b,c Homojenlik grupları küçük harflerle verilmiştir, X: Aritmetik ortalama, S: standart sapma

Deneme levhalarındaki 2 ve 24 saat süre sonunda kalınlık artışı değerleri, kontrol örneği 2 saat $\% 11.34$ ve 24 saat $\% 40.55$ değerinden yüksek çıkmıştır. Kalınlığına artış miktarı 2 saat süre sonunda en fazla dolomit $\% 25$ (\%15.72) meydana gelirken, 24 saat süre sonunda da en fazla kalınlık artışı dolomit \%25' te (\%48.51) meydana gelmiştir. Oysaki HDF levhalarda su alma \%18 civarındadır [9]. Şekil 2 ve Şekil 3'de 2 ve 24 saat su alma ve kalınlığına şişme oranları gösterilmiştir 


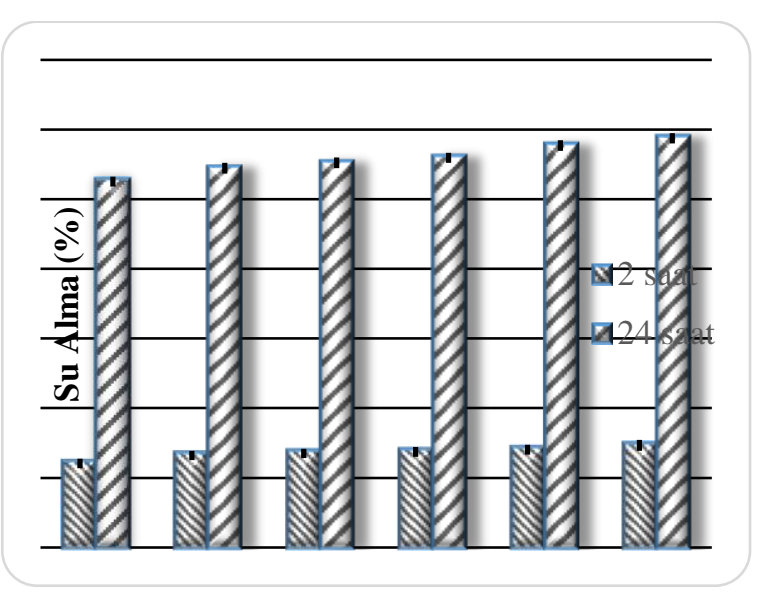

Şekil 2. HDF levhaların 2 ve 24 saat su alma değerlerindeki değişim

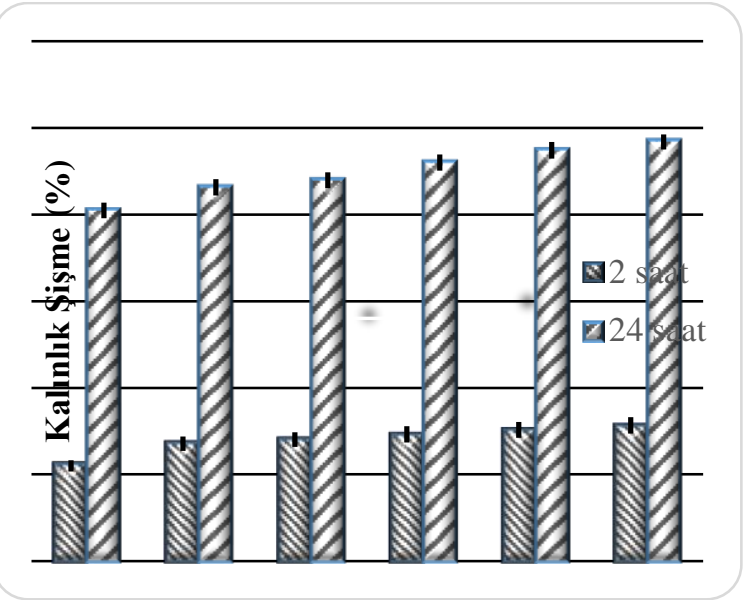

Şekil 3. HDF levhaların 2 ve 24 saat kalınlık şişme değerlerindeki değişim

Şekil 2 ve Şekil 3' de görüldüğü üzere dolomit minerali konsantrasyon artışı ile örneklerin 2 ve 24 saat su alma ve kalınlığına şişme miktarı artmıştır. Çizelge 1' de dolomit minerali kimyasal analiz sonuçlarında belirtildiği gibi $\mathrm{CaO}$ (\%31.10) ve $\mathrm{MgO}$ (\%21.04) içermesi nedeni ile higroskopik bir özellik göstermektedir. Dolomit mineralinin higroskopik özellik taşımaları nedeni ile muamele edilmiş deneme levhalarının su alma oranının artması önceki çalışmalara uygunluk göstermiştir. Katılım oranının artması ile bağ yapmayan kimyasal maddeler lif-lif bağlanmasını olumsuz etkileyerek yüzeylerde toplanması ile rutubetin daha fazla çekilmesine neden olmaktadır [10]. Dolayısıyla kalınlık artışı beklenilen bir sonuç olarak değerlendirilmektedir. Su alma özelliği lifler arasına su itici kimyasal maddeler eklenmesi, kalınlık artışı ise levha kenarlarında özellikle parke üretiminde parafin sürülmesi ile azaltılabilmektedir.
Tablo 5. HDF levhaların eğilme direnci ve elastikiyet modülü değerleri $\left(\mathrm{N} / \mathrm{mm}^{2}\right)$

\begin{tabular}{|c|c|c|c|c|}
\hline \multirow{2}{*}{$\begin{array}{c}\text { Mineral } \\
\text { madde }\end{array}$} & \multicolumn{2}{|c|}{ Eğilme Direnci } & \multicolumn{2}{c|}{$\begin{array}{c}\text { Elastikiyet } \\
\text { Modülü }\end{array}$} \\
\cline { 2 - 5 } & $\mathrm{N} / \mathrm{mm}^{2}$ & $\mathrm{~S}$ & $\mathrm{~N} / \mathrm{mm}^{2}$ & $\mathrm{~S}$ \\
\hline Dol \%05 & $40.06^{\mathrm{c}}$ & 3.36 & $2612^{\mathrm{b}}$ & 49 \\
\hline Dol \%10 & $39.86^{\mathrm{c}}$ & 3.71 & $2457^{\mathrm{ab}}$ & 147 \\
\hline Dol \%15 & $36.28 \mathrm{~b}^{\mathrm{c}}$ & 3.96 & $2376^{\mathrm{ab}}$ & 236 \\
\hline Dol \%20 & $32.16^{\mathrm{ab}}$ & 3.22 & $2286^{\mathrm{ab}}$ & 123 \\
\hline Dol \%25 & $29.56^{\mathrm{a}}$ & 4.67 & $2265^{\mathrm{a}}$ & 211 \\
\hline Kontrol & $48.54^{\mathrm{d}}$ & 2.42 & $3439^{\mathrm{c}}$ & 277 \\
\hline $\begin{array}{c}\text { Duncan Testi } \\
\text { P Değeri }\end{array}$ & 0.000 & --- & 0.000 & --- \\
\hline
\end{tabular}

a ,b ,c Homojenlik grupları küçük harflerle verilmiştir, S: standart sapma

$\mathrm{P}<0.05$ önem düzeyinde su alma, kalınlığına şişme 2 saat ve 24 saat değerlerinde dolomit minerali kullanım parametrelerinin istatistik olarak önemli olduğu bulunmuştur. Yanmayı geciktirici etki amacı ile ve dolomit mineralinin farklı konsantrasyonlarının, liflere eklenmesi ile elde edilen deneme levhalarının eğilme direnci ve elastikiyet modülüne ait ölçümler Tablo 5'de verilmiştir.

Eğilme direnci kontrol örneği eğilme direnci $48.54 \mathrm{~N} / \mathrm{mm}^{2}$ iken en düşük ölçüm değeri dolomit \%25 deneme levhalarında $29.56 \mathrm{~N} / \mathrm{mm}^{2}$ olarak bulunmuştur. Aynı şekilde elastikiyet modülü kontrol örneği 3439 $\mathrm{N} / \mathrm{mm}^{2}$ iken en düşük değer dolomit $\% 25$ levha örneğinde $2265 \mathrm{~N} / \mathrm{mm}^{2}$ olarak bulunmuştur. Eğilme direnci ve elastikiyet modülünü dolomit minerali eklemesi olumsuz etkilemiştir. Dolomit minerali artan katılım oranına da bağlı olarak lifler arasındaki lif-lif bağ yapısını olumsuz etkilemektedir. Dönmez ve ark. [11], çimentolu yonga levha üretiminde, borlu bileşik kullanım oranı arttıkça eğilme direnci ve elastikiyet modülü değerlerinde düşüş olduğunu belirtmişlerdir. Şekil 4 ve Şekil 5' te bu düşüşler gösterilmiştir.

$\mathrm{P}<0.05$ önem düzeyinde eğilme direnci ve elastikiyet modülü ölçümlerinde dolomit minerali kullanım parametrelerinin istatistik olarak önemli olduğu bulunmuştur. 


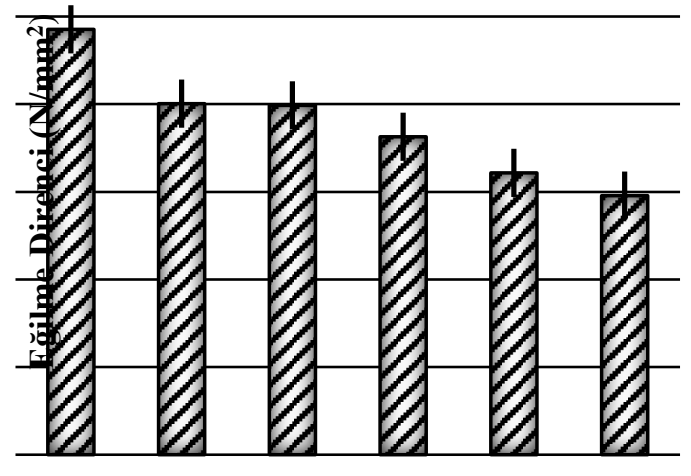

Şekil 4. HDF levhaların eğilme direnci değerlerindeki değişim $\left(\mathrm{N} / \mathrm{mm}^{2}\right)$

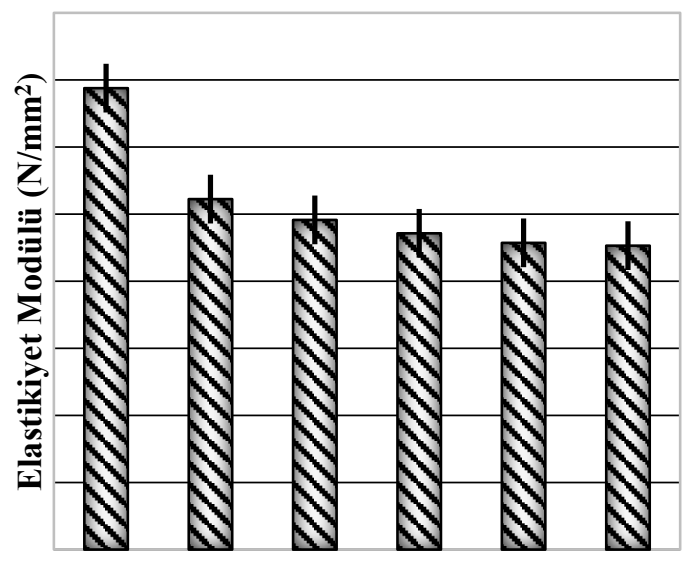

Şekil 5. HDF levhaların elastikiyet modülü değerlerindeki değişim $\left(\mathrm{N} / \mathrm{mm}^{2}\right)$

\subsection{Limit Oksijen İndeksi (LOI) Test Bulguları}

LOI değerleri polimerlerin kimyasal yapıları ile yakından ilgilidir. Yanma özelliği materyallerin içerdiği hidrojen ve karbon moleküllerine bağlı olarak değişmektedir. LOI değeri \%25 den küçük olanlar çok kolay yanan, \%25 den büyük olanlar ise havada kendiliğinden sönebilen materyal grubu olarak ifade edilir [12]. Tablo 6' da görüldüğü gibi HDF levhalara dolomit eklemesi ile oksijen indeks değerlerinde artma olduğu belirlenmiştir. Dolomit minerali eklemesi yanma ve oksijen indeks değerlerini olumlu etkilemişstir. Kontrol örneği değerine (\%24) göre iyileşme dolomit mineralinin artması ile de gelişmiştir. En iyi yanmayı geciktirme etkisi, \%25 dolomit minerali eklenen deneme örneklerinde tespit edilmiş ve LOI değeri \%27 olarak bulunmuştur. Benzer çalışmalarda bor bileşiklerinin de oksijen indeksini geliştirdiği bulunmuştur [13,14,15]. LOI değeri havada yanma esnasında ihtiyaç duyulan oksijen miktarını ifade ettiği için LOI değeri \%25 den büyük olanlar güç tutuşan materyal sınıfına dâhil edilirler [16]. Dolomit \%15 örneklerinde bu değerin elde edildiği belirlenmiştir.

Tablo 6. Dolomit minerali ilave edilmesi ile üretilen HDF deneme levhalarına ait ortalama oksijen indeksi ölçümleri

\begin{tabular}{|c|l|c|}
\hline Sıra No & $\begin{array}{c}\text { Dolomit Mineral } \\
\text { Oranı (\%) }\end{array}$ & Oksijen İndeksi (\%) \\
\hline 1 & Dol \%5 & 24.25 \\
\hline 2 & Dol \%10 & 24.75 \\
\hline 3 & Dol \%15 & 25.50 \\
\hline 4 & Dol \%20 & 26.00 \\
\hline 5 & Dol \%25 & 27.00 \\
\hline 6 & Kontrol & 24.00 \\
\hline
\end{tabular}

\section{SONUÇ VE ÖNERILER}

$\mathrm{Bu}$ araştırmada lif içerine dolomit minerali eklemenin HDF levhaların fiziksel (su alma, kalınlık şişme), mekanik (eğilme direnci, elastikiyet modülü) ve LOI üzerine etkisi incelenmiştir. Elde edilen bulgulara göre:

1. HDF levhaların 2 ve 24 saat su alma değerlerinde, dolomit mineralinin $\mathrm{CaO}$ ve $\mathrm{MaO}$ içeriğinden dolayı su alma özelliğinde artış olduğu tespit edilmiştir. Dolomit minerali eklemesi ile artışın fazlalaştı̆̆ bulunmuştur.

2. Dolomit mineralinin eklenen katılım miktarına bağlı olarak 2 ve 24 saat kalınlığına şişme özelliği üzerine olumsuz etki yaptığı belirlenmiştir.

3. Dolomit mineralinin HDF levhaların yanma direncini olumlu etkilediği ve eklenme oranına bağlı olarak da geliştirdiği bulunmuştur. LOI testinde en olumlu yanma direnci özelliğine dolomit $\% 25$ eklenme oranında ulaşılmıştır (\%27).

4. Dolomit minerali yanmayı geciktirici mineral olarak modifiye edilerek kullanım konusu ele alınmalıdır.

\section{KAYNAKLAR}

[1]. Roger, R.M., (2005). "Handbook of wood chemistry and wood composites", 383.

[2]. White, R. H., and Sweet, M. S., (1992). "Flame retardancy of wood: Present status, recent problems, and future fields", Proceedings of 3rd Annual BCC Conference of Flame Retardancy, 250-257.

[3]. Ayrilmis, N., Kartal, S. N., Laufenberg, T., Winandy, J. E., White, R. H., (2005). "Physical and mechanical properties, fire, decay, and termite resistance of treated oriented strandboard", Forest Products Journal, 55(5), 74-81. 
[4]. Kozlowski R., Helwig, M., Przepiera, A., (1995). “ Light-weight, environmentally friendly, fire retardant composite boards for paneling and construction", Inorganic Bonded Wood and Fiber Composite Materials, 6-11.

[5]. Adesakin A.O., Ajayi O.O., Imosili P.E., Attahdaniel B.E. and Olusunle S.O.O., (2013). "Characterization and Evaluation of Mechanical Properties of Dolomite as Filler in Polyester", Chemistry and Materials Research, 3, 8.

[6]. TS EN 317, (1999). Yonga Levhalar ve Lif Levhalar - Su içerisinde Daldırma işleminden Sonra Kalınlığına Şişme Tayini, TSE, Ankara.

[7]. TSE EN 310, (1999). Ahşap Esaslı LevhalarEğilme Dayanımı ve Eğilme Elastikiyet Modülünün Tayini. TSE, Ankara.

[8]. ASTM 2863-09 (2006). Standart test method for measuring the minimum oxygen concentration to support candle-like combustion of plastics, ASTM International, United State.

[9]. Döngel, N., (2005). “Ahşap ve Ahşap Esaslı Kaplama Malzemelerinin (Parke) Teknik Özellikleri”, Doktora Tezi, Fen bilimleri Ens., Ankara.

[10]. Cremonini, C., Pizzi, A. ve Tekely, P., (1996). "Improvement of PMUF Adhesives, Performance For Fireproof Plywood", Holz and Ron-und Werkstoffe, 54, 43-47.

[11]. Dönmez, Ç., A., Kalaycıŏlu, H., Ertaş, M., Alma, M.H., (2009). "Borik asit ve çinko borat kullanımının Çimentolu yonga Levha Özellikleri Üzerine Etkisi”, 4. Uluslararası bor sempozyumu, 15-17 Ekim, Eskişehir.

[12]. Kayan, S., (2004). "Tekstil Materyallerinin Yanma Mekanizması ve Limit Oksijen indeks Değerleri”. Marmara Üniversitesi FBE Tekstil Eğitimi Anabilim Dalı. Enstrümantal Analiz Dersi, İstanbul.

[13]. Özdemir, F., Tutuş, A., (2013). "Yanmayı geciktirici kimyasal madde ilavesinin yüksek yoğunluklu lif levhanın 1sı iletkenliği ve limit oksijen indeksi üzerine etkileri”, SDU Faculty of Forestry Journal, 14, 121-126

[14]. Baysal, E., (2002). "Determination of oxygen index levels and thermal analysis of scots pine impregnated melamine formaldehyde-boron combinations", Journal of Fire Sciences, 20(5), 373-389.

[15]. Sain, M., Park, S.H., Suhara, F., Law, S., (2004). "Flame retardant and mechanical properties of natural fibre-PP composites containing magnesium hydroxide. Polymer Degradation and Stability", 83(2), 363-367.

[16]. Chen, S., Zheng, Q., Ye, G., Zheng, G., (2006). "Fire retardant properties of the viscose rayon containing alkoxycyclotriphosphazene", Journal of Applied Polymer Science, 102, 698-702. 